\title{
Fibrinogen as a risk factor for premature myocardial infarction in Iranian patients: A case control study
}

\author{
Mohammad Shojaie \\ Morteza Pourahmad \\ Ahad Eshraghian \\ Hamid Reza Izadi \\ Farzan Naghshvar
}

Peymanieh Hospital, Internal Medicine Department, Jahrom University of Medical Sciences, Jahrom, Fars, Iran
Correspondence:Ahad Eshraghian Internal Medicine Department, Shiraz University of Medical Sciences, Fars Province, Iran

Tel +98 79 I3340406

Email eshraghiana@yahoo.com
This article was published in the following Dove Press journal:

Vascular Health and Risk Management

II August 2009

Number of times this article has been viewed

Background: Premature myocardial infarction with life-threatening complications may become epidemic in some Asian and African countries and especially Iran. Fibrinogen is considered as one of the probable risk factors of myocardial infarction. The aim of our study was to assess fibrinogen levels as an etiology of premature myocardial infarction in young Iranian men.

Findings: A case-control study was conducted between May 2005 and May 2007 to investigate the association between serum total fibrinogen level and myocardial infarction in men aged younger than 55 years admitted to the cardiac care units of Peymanieh and Motahari Hospitals affiliated to Jahrom University of Medical Sciences, Iran. The mean age of patients was $45.2 \pm 4$ years in patients with premature myocardial infarction and $47.06 \pm 4.5$ years in the control group $(p=0.085)$. There were no statistically significant relationships between the two groups in history of premature myocardial infarction in their first-degree relatives $(\mathrm{p}=0.05)$, cigarette smoking $(\mathrm{p}=0.46)$, diabetes $(\mathrm{p}=0.49)$, or hypertension $(\mathrm{p}=1)$. The mean plasma fibrinogen in patients $(354.9 \pm 60 \mathrm{mg} / \mathrm{dL})$ was elevated markedly compared with the control group $(329 \pm 73 \mathrm{mg} / \mathrm{dL})$. Hyperfibrinogenemia ( $>340 \mathrm{mg} / \mathrm{dL}$ ) was detected in $81.8 \%$ of patients and $57.5 \%$ of controls $(95 \%$ confidence interval, odds ratio $=3.3 ; \mathrm{p}=0.036)$.

Conclusion: This study introduced fibrinogen as a risk factor for premature coronary artery disease in Iranian men.

Keywords: myocardial infarction, cigarette, hypertension, diabetes, fibrinogen

\section{Background}

The notion that fibrinogen is related to cardiovascular diseases was first aired in the $1950 \mathrm{~s},{ }^{1}$ when its level was found to be increased in patients with ischemic heart disease. During recent years, many prospective epidemiological studies have reported positive associations between the risk of coronary heart disease (CHD) and plasma fibrinogen levels. ${ }^{2-5}$ Fibrinogen is the major coagulation protein in blood by mass, the precursor of fibrin, and an important determinant of blood viscosity and platelet aggregation. ${ }^{6-9}$ Because fibrinogen levels can be reduced considerably by lifestyle interventions that also affect levels of established risk factors (such as regular exercise, smoking cessation, and moderate alcohol consumption), there is interest in the possibility that measurement (or modification) of fibrinogen may help in disease prediction or prevention. ${ }^{6-8,10}$

Furthermore there are few studies evaluating the role of fibrinogen in premature myocardial infarction (MI) as an independent risk factor for developing coronary artery disease. Iran is a developing country with a high and growing prevalence of coronary artery disease. The incidence of acute coronary syndromes during recent years has increased surprisingly, especially among young Iranian men. submit your manuscript | www.dovepress.com

Dovepress 
In the present study we examined the relation between serum total fibrinogen concentration and premature $\mathrm{MI}$ in Iranian patients to further elucidate the role of fibrinogen as an independent risk factor for acute CHD events.

\section{Methods}

\section{Study design}

A case-control study was conducted between May 2005 and May 2007 to investigate the association between serum fibrinogen level and MI in men aged younger than 55 years admitted to the cardiac care units of Peymanieh and Motahari Hospitals affiliated to the Jahrom University of Medical Sciences, Iran. The diagnosis of acute myocardial infarction (AMI) was based on the presence of ischemic chest pain of at least 30 minutes' duration and creatine kinase (CK) elevation of at least twice the upper normal limit, with $\mathrm{CK}$, muscle and brain (CK-MB) isoenzyme concentration of at least $6 \%$ of the peak $\mathrm{CK}$ value, accompanied by dynamic ST-segment elevation or depression of $1 \mathrm{~mm}$ or more in at least two adjacent leads. Premature AMI was defined as having the above-mentioned criteria in patients aged younger than 55 years.

Patients and controls that had hyperlipidemia were excluded from the study. At that time the patients were considered to be in a stable clinical and metabolic state and not in an acute phase for plasma fibrinogen. ${ }^{11}$

Among 200 men with a first episode of AMI who were admitted within 12 hours of symptoms onset, 33 were enrolled as cases. None of these 33 patients had recurrent MI during their follow up and all of them completed the study. Controls were 33 men aged under 55 years who survived to the end of the study period free from incident MI and stroke. They were randomly selected with frequency matching to cases by the site of residence and by age group. They also were matched with case group regarding other CHD risk factors such as diabetes mellitus, hypertension, and cigarette smoking. Participating case and control subjects were asked to complete a questionnaire to obtain information on any history of known or suspected cardiovascular risk factors, including physician-diagnosed diabetes, hypertension, or high cholesterol, cigarette smoking, height and weight, alcohol consumption, physical activity, history of MI in first-degree relatives and demographic characteristics.

\section{Blood collection and laboratory methods}

To determine fibrinogen, we obtained a $1.8-\mathrm{mL}$ venous blood specimen after a 12-hour fast from $33 \mathrm{MI}$ case subjects and 33 control subjects into vacuum tubes containing $0.2 \mathrm{~mol} / \mathrm{L}$ trisodium citrate $(9: 1 \mathrm{blood} /$ citrate, $\mathrm{vol} / \mathrm{vol})$. The blood was centrifuged immediately for about 15 minutes and the obtained plasma was then frozen at $-20^{\circ} \mathrm{C}$. Case blood samples were obtained at least one year after the MI. Plasma fibrinogen level was determined using TEClot Fib Kit-10 (Lot No: 500502; TECO GmbH, Neufahrn, Germany). A serum fibrinogen level more than $340 \mathrm{mg} / \mathrm{dL}$ was considered high. The study was approved by the local ethics committee of each hospital and each patient gave their written informed consent. This study was conducted in accordance with the Declaration of Helsinki.

\section{Statistical analysis}

Data were collected and analyzed using SPSS software (SPSS Inc., Chicago, IL, USA). A p value of less than 0.05 was considered significant. Comparisons of frequencies have been carried out using $\chi^{2}$ tests or Fisher's exact test as appropriate. The research council of Jahrom University of Medical Sciences supported our data collection and helped purchase the required equipment.

\section{Results}

The mean age of our case and control subjects was $45.2 \pm 4$ years and $47.06 \pm 4.5$ years, respectively $(\mathrm{p}=0.085)$. Among patients with premature AMI, seven $(21.2 \%)$ had history of premature MI in their first-degree relatives whereas six control subjects $(18.02 \%)$ had family history of premature AMI $(\mathrm{p}=0.05) .18$ patients $(54.5 \%)$ and 15 control subjects $(45.4 \%)$ were cigarette smokers $(p=0.46)$. Two patients were diabetic $(6.1 \%)$, but none of the control group were diabetic $(\mathrm{p}=0.49)$. In both case and control groups, five individuals (15.2\%) had hypertension $(\mathrm{p}=1)$ (Table 1).

Twenty-seven patients $(81.8 \%)$ had elevated fibrinogen levels $(>340 \mathrm{mg} / \mathrm{dL})$. In 33 control group individuals, $19(57.5 \%)$ had elevated fibrinogen levels (odds ratio $[\mathrm{OR}]=3.3$ ). The plasma fibrinogen level was significantly

Table I CHD risk factors in case and control groups

\begin{tabular}{llll}
\hline & Case & Control & P-value \\
\hline Age (year) & $45.2 \pm 4$ & $47.06 \pm 4.5$ & NS \\
Cigarette smoking & 18 & 15 & NS \\
Diabetes mellitus & 2 & 0 & NS \\
Hypertension & 5 & 5 & NS \\
Family history of premature MI & 7 & 6 & NS \\
\hline
\end{tabular}

Abbreviations: $\mathrm{CHD}$, coronary heart disease; MI, myocardial infarction; NS, not statistically significant. 
higher in case subjects than in the control group $(\mathrm{p}=0.036)$ (Table 2).

\section{Discussion}

The present study implies that high serum fibrinogen levels are a risk factor for premature AMI. As described earlier, for this study we prepared venous samples for detection of fibrinogen levels one year after MI to show that fibrinogen concentrations return to basal levels. Using this method there was no need to store serum samples for a long period of time and the potential bias existing in case control studies about falsely elevated levels of fibrinogen after MI would diminish.

We obtained venous blood specimen from both case and control groups after a 12-hour fast to eliminate the probable effect of diet on fibrinogen levels. Both case and control groups were matched regarding other risk factors of coronary artery disease such as hypertension, diabetes mellitus, cigarette smoking, hyperlipidemia, age, sex, and body mass index. Several prospective and cross-sectional studies have revealed that plasma fibrinogen levels have a strong predictive value for CHD and stroke. In a large, population-based, prospective study, the Atherosclerosis Risk in Communities (ARIC) Study, plasma fibrinogen was found to be an important risk factor for CHD in women. ${ }^{12}$ In an Iranian study performed in 2007, serum fibrinogen levels were significantly higher in patients with AMI with ST-change. ${ }^{13}$ Other studies are in favor of the hypothesis of a multifactorial etiology of CHD in young patients suffering MI. ${ }^{14}$

The physiological importance of elevated plasma fibrinogen levels is not fully understood. The mechanisms by which plasma fibrinogen may be involved in atherothrombosis are theological alterations, increased platelet aggregation tendency, increased fibrin formation, and stimulation of vascular cell proliferation and migration, with increasing plasma fibrinogen levels. ${ }^{15}$ Thus, elevated plasma fibrinogen levels, whatever their origin - genetic, as part of an

Table 2 Normal and elevated fibrinogen level in case and control groups

\begin{tabular}{lllllll}
\hline & \multicolumn{2}{l}{ Case } & & & \multicolumn{2}{l}{ Control } \\
\cline { 2 - 3 } \cline { 5 - 6 } \cline { 5 - 6 } & Number & Percent & & Number & Percent \\
\hline $\begin{array}{l}\text { Normal fibrinogen } \\
(<340 \mathrm{mg} / \mathrm{dL})\end{array}$ & 6 & 18.2 & & 14 & 42.5 \\
$\begin{array}{l}\text { Hyperfibrinogenemia } \\
(>340 \mathrm{mg} / \mathrm{dL})\end{array}$ & 27 & 81.8 & & 19 & 57.5 \\
\hline
\end{tabular}

inflammation reaction, or some other reason - may cause a hypercoagulative state that could influence the degree and duration of thrombus formation at the time of coronary injury.

Elevated fibrinogen concentrations could be due to the disease (ie, MI) or to an underlying vascular disease (eg, atherosclerosis) rather than as a cause of MI or vascular disease. It is possible that because serum has often been stored for a considerable period of time, the measurement of serum levels of fibrinogen may be compromised.

This study was conducted among male patients and the sample size is relatively low. Further studies on the role of fibrinogen in acute coronary syndromes in other age groups and sexes are necessary.

The role of plasma fibrinogen levels in premature coronary artery disease is less clear. The prevalence of cardiovascular disease especially among the youth is growing in Iran and further investigations for finding risk factors in the Iranian population seem to be of great importance.

Our findings suggested that higher fibrinogen levels are associated with premature coronary artery disease in the Iranian population.

\section{Disclosures}

The authors would like to thank the research council of Jahrom University of Medical Sciences which provided financial support for this study. We also thank all nursing staff at the cardiac care units of Peymanieh and Motahari Hospitals of Jahrom University of Medical Sciences, Iran. The authors report no conflicts of interest in this work.

\section{References}

1. Losner S, Volk BW, Wilensky ND. Fibrinogen concentration in acute myocardial infaction. Arch Intern Med. 1954;93:231-238.

2. Cantin B, Després JP, Lamarche B, et al. Association of fibrinogen and lipoprotein (a) as a coronary heart disease risk factor in men (Quebec Cardiovascular Study). Am J Cardiol. 2002;89:662-666.

3. Wilhelmsen L, Svärdsudd K, Korsan-Bengtsen K, Larsson B, Welin L, Tibblin G. Fibrinogen as a risk factor for stroke and myocardial infarction. N Engl J Med. 1984;311:501-505.

4. Yano K, Grove JS, Chen R, Rodriguez BL, Curb JD, Tracy RP. Plasma fibrinogen as a predictor of total and cause-specific mortality in elderly Japanese-American men. Arterioscler Thromb Vasc Biol. 2001;21:1065-1070

5. Lind P, Hedblad B, Stavenow L, Janzo L, Eriksson KF, Lindgärde F. Influence of plasma fibrinogen levels on the incidence of myocardial infarction and death is modified by other inflammation-sensitive proteins: a long-term cohort study. Arterioscler Thromb Vasc Biol. $2001 ; 21: 452-458$.

6. Danesh J, Collins R, Peto R, Lowe GDO. Haematocrit, viscosity, erythrocyte sedimentation rate: meta-analyses of prospective studies of coronary heart disease. Eur Heart J. 2000;21:515-520.

7. Lowe GDO. Fibrinogen and cardiovascular disease: historical introduction. Eur Heart J. 1995;16(Suppl A):2-5. 
8. Smith EB. Fibrinogen, fibrin and the arterial wall. Eur Heart J. 1995;16(Suppl A):11-14.

9. Smith EB, Crosbe I. Fibrinogen and fibrin in atherogenesis. In: Ernst E, Koenig W, Lowe GDO, Meade TW, editors. Fibrinogen: A "New" Cardiovascular Risk Factor. Vienna, Austria: Blackwell-MZV; 1992. pp. 4-10.

10. Folsom AR. Epidemiology of fibrinogen. Eur Heart J. 1995;16(Suppl A): $21-23$.

11. Fulton RM, Duckett K. Plasma-fibrinogen and thromboemboli after myocardial infarction. Lancet. 1976;2:1161-1164.

12. Folsom A, Wu K, Rosamond W, Sharrett A, Chambless L. Prospective study of hemostatic factors and incidence of coronary heart disease: the Atherosclerosis Risk in Communities (ARIC) Study. Circulation. 1997;96:1102-1108.
13. Omran MT, Asadollahi S. The measurement of serum fibrinogen levels in patients with acute coronary syndrome. Saudi Med J. 2007;28(9):1350-1352.

14. Lewandowski K, Kwaśnikowski P, Elikowski W, Zawilska K. Myocardial infarction in patients aged less than 40 years. Frequency of Bcll polymorphism in the fibrinogen beta-chain gene and plasma fibrinogen. Kardiol Pol. 2003;59(9):205-212.

15. Ernst E, Koenig W. Fibrinogen and cardiovascular risk. Vasc Med. 1997;2:115-125.

\section{Publish your work in this journal}

Vascular Health and Risk Management is an international, peerreviewed journal of therapeutics and risk management, focusing on concise rapid reporting of clinical studies on the processes involved in the maintenance of vascular health; the monitoring, prevention and treatment of vascular disease and its sequelae; and the involvement of metabolic disorders, particularly diabetes. This journal is indexed on PubMed Central and MedLine. The manuscript management system is completely online and includes a very quick and fair peer-review system, which is all easy to use. Visit http://www.dovepress.com/ testimonials.php to read real quotes from published authors. 